\title{
EXTRACTS OF SUNFLOWER HULLS: THEIR ANTIOXIDANT ACTIVITY ON LIPIDS OF COOKED MACKEREL FISH
}

\author{
Gamal F.M. ${ }^{1}$ \& Fakhriya S.T. ${ }^{2}$ \\ ${ }^{1}$ Food Technology Dept, National Research Center, Cairo, Egypt. \\ ${ }^{2}$ Fats and Oils Dept, National Research Center, Cairo, Egypt.
}

\begin{abstract}
Sunflower (Helianthus annus $L$ ) hulls that have been investigated in the present work include the hulls from variety Giza 1. and hulls from hybrid Vedoc and white seeds. Methanol (M), ethanol (E), acetone (A) and ethyl acetate (EA) have been investigated as extracting solvents for the phenolic compounds present in the hulls. Solvent(S): hull $(\mathrm{H})$ ratio $(\mathrm{v} / \mathrm{w})$ examined were 5:1, 7:1, and 10:1. Methanol, ethanol, acetone and ethyl acetate at a S: $\mathrm{H}$ ratio $7: 1$ extracted the highest quantities of phenolic compounds from Vedoc hulls, extracting 337.9, 367.6, 312.3 and $272.9 \mathrm{mg} / 1$. extract, respectively. The highest extraction for Giza 1 and white hulls was achieved at S:H ratio 7:1 with ethanol. Vedoc and Giza 1 hull extracts were examined for their antioxidant activity using the $\beta$-carotene / linoleate system. All extracts exhibited antioxidant activity. Antioxidative power for both hulls were in the following descending order ME $\geq \mathrm{EE}$ $>\mathrm{AE}>\mathrm{EAE}$. Compared to BHT, ethanolic extract of Vedoc hulls possessed $88.5 \%$ and $90.5 \%$ of the antioxidant power of BHT-200 and BHT-50, respectively. For further confirmation, the ethanolic extract of Vedoc hulls (EEV) was investigated on a fish meat model system. Mackerel fish was chosen for this purpose. Different concentrations of EEV and BHT were added to minced mackerel meat along with a control and cooked at $75 \pm 2^{\circ} \mathrm{C}$ for $30 \mathrm{~min}$. After cooling to room temperature, the cooked samples were stored under refrigerated conditions at $4^{\circ} \mathrm{C}$ for 7 days. The thiobarbituric acid (TBA) values proved that ethanol extract of Vedoc sunflower hulls (EEV)-100 had a power of inhibiting lipid oxidation comparable to BHT-200, while EEV-500 and EEV-1000 proved to exhibit antioxidant activity superior to BHT-200 in the mackerel meat model system. The highest \% inhibition of TBA formation was achieved with EEV1000 at day $5(75.05 \%)$. Surface colour was measured by Hunter Lab. Values of $\mathrm{L}^{*}$ and $\mathrm{b}^{*}$ increased while $\mathrm{a}^{*}$ values decreased during the storage period, but addition of EEV resulted in meat samples with less $\mathrm{L}^{*}$ and $\mathrm{b}^{*}$ values and higher $\mathrm{a}^{*}$ values than the control.
\end{abstract}

Keywords : sunflower hulls, phenolic compounds, antioxidants, BHT, mackerel, TBA, Hunter colour.

\section{INTRODUCTION}

Oilseed hulls are believed to shelter the oil against oxidation, thus must contain antioxidant compounds. The major use of seed hulls include, livestock bedding, composting land application, filler material, and in animal feed mixtures. Research have proved that activated carbon can be prepared from seed hulls to be utilized as adsorbents in wastewater treatment (John \& Marshall (1994), and in bleaching of edible oils (Aly \& Girgis 2000; Omar et al. 2003). Recent investigations indicate that seed hull exhibited antioxidant activity including: rice hulls (Asamarai et al. 1996, Wu et al. 1994), navy bean hulls (Onyenecho \& Hettiarachchy 1991), buckwheat hulls (Watanabe et al. 1997), oat hulls (Xing \& White 1997), rapeseed hulls (Amarowicz et al. 2000), peanut hulls (Duh \&
Yen 1995; Yen \& Duh 1995), and sesame coat (Chang et al. 2002 ).

Sunflower seeds are covered with highly fibrous hulls which comprise about $15-25 \%$ of the seed. These hulls are mostly used for livestock bedding. A small amount of sunflower hulls can be added to animal feed as a source of fiber because of its needle like nature which can damage the gastrointestinal tract. It was experimented on the use of sunflower hulls as supplementary fuel to coalfired power plants (Crum et al. 1992).

Lipid and lipid-soluble substances that may be susceptible to oxidation are present in almost all foods. Lipid peroxidation can result in rancidity in the finished products and make them unacceptable to consumers. Furthermore, oxidation can cause other degrading effects 
such as discoloration, vitamin destruction, nutritional losses and polymerization (Yen \& Duh 1995). In addition, toxic substances formed by lipid peroxidation may lead to other adverse effects such as carcinogenesis, mutagenesis, and aging (Yagi 1990). The addition of antioxidants to foods is one of the most effective means in retarding lipid oxidation. There is currently an interest in replacing synthetic antioxidants with natural ones (Ito et al. 1982 ). On the other hand, Velioglu et al. (1998) and Pedrosa et al. (2000), reported the presence of phenolic compounds in sunflower hulls.

The present work was designed with the aim of examining the antioxidant activity of three different sunflower hulls as extracted with different organic solvents at different solvent: hull ratio. The total phenolic content of these extracts were determined as well as their antioxidant activity in vitro. The best extract with optimum antioxidant activity was chosen to be tested in a fish (mackerel) meat model system.

\section{MATERIALS AND METHODS}

\section{Materials}

Sunflower seeds (Helianthus annus $L$ ) varieties namely: Giza 1 (striated), hybrid Vedoc (black) were supplied by the Agricultural Seed Research Station, Ministry of Agriculture, Dokki, Giza, Egypt, and a (white) hybrid was bought from a local market. Sunflower seeds were partially crushed and sieved to separate hulls by aspiration, the hulls were then ground using a Wiley Mill (Teactor Cemoetc 1090, Hoganas, Sweden).

Frozen mackerel (Scomber scombrus) was bought from a local market. The white muscle was separated and homogenized using a Waring blender (Model 33BL73, Waring Products, New Hartford, CT). The meat was then packaged in polyethylene pouches and kept in a freezer to be used later.

\section{Methods}

\section{Extraction of total phenolic compounds}

Ground sunflower hulls of the three types of sunflower were extracted with several organic solvents namely, methanol (M), ethanol (E), acetone (A) and ethyl acetate (EA) at solvent to hull ratios of 5:1, 7:1 and 10:1.

Extraction was carried out using shaking incubator at room temperature overnight, filtered through Whatman No. 4 filter paper. The residue was re-extracted in the same manner. Two filtrates were combined and evaporated on a rotary evaporator (Rotavapor R-124-BUCHISwitzerland) at $40^{\circ} \mathrm{C}$ to dryness.

\section{Determination of total phenolic compounds}

Total phenolic compounds were quantitatively determined according to Hung et al. (2002) by measuring the absorbance at $765 \mathrm{~nm}$ using Folin Ciocalteu's phenol reagent. one $\mathrm{ml}$ of Folin Ciocalteu's phenol reagent of (1:10) dilution was added to $0.2 \mathrm{ml}$ of the different solvent extracts of sunflower hulls, $0.8 \mathrm{ml}$ of the $7.5 \%(\mathrm{w} / \mathrm{v})$ sodium carbonate was added and mixed. The mixture was left for $30 \mathrm{~min}$. for colour development. The absorbance $\left(\mathrm{A}_{765}\right)$ was read against milli-Q water. The concentration of phenol groups was calculated from a standard curve obtained by subjecting various amounts of gallic acid to the same treatment as the test samples. The equation for the standard curve was as follows:

$$
\mathrm{PG}=95.1 . \mathrm{A}_{765}-2.6
$$

Where PG is the concentration of phenol groups (mg/l.).

\section{Determination of antioxidant activity (AOA)}

Antioxidant activity of hull extracts and standard BHT (50 and 200ppm) was determined according to the $\beta$-carotene bleaching method following a modification of the procedure described by Marco (1968). For a typical assay, one $\mathrm{ml}$ of $\beta$-carotene solution $(0.2 \mathrm{mg} \beta$ carotene $/ \mathrm{ml}$ in chloroform) was added to round bottom flasks containing $0.2 \mathrm{ml}$ linoleic acid and $0.2 \mathrm{ml}$ of Tween 20. After evaporation to dryness under vacuum at room temperature, oxygenated distilled water $(50 \mathrm{ml})$ was added and the mixture was shaken to form a liposome solution (emulsion). A $5 \mathrm{ml}$ aliquot of emulsion was placed in test tubes contained $0.2 \mathrm{ml}$ of $80 \%$ methanol (as a control) or corresponding hull extract or standard and the mixture was thoroughly mixed. The samples were then subjected to thermal autoxidation at $50^{\circ} \mathrm{C}$ for $2 \mathrm{hrs}$. (Velioglu et al. 1998). The absorption of the solution at $470 \mathrm{~nm}$ was measured using a spectrophotometer (Shimadzu UV-Visible Recording Spectrophotometer, Model UV240 Graphtcord) by taking measurements at $15-20$ min. intervals. The rate of bleaching of $\beta$ carotene was calculated by fitting linear regression to data over time. All samples were assayed in triplicate. Antioxidant activity (AOA) was calculated as \% inhibition relative to control using the following equation (Al-Shaikhan et al. 1995) 


$$
\text { AOA } \%=\frac{\mathrm{R}_{\text {control }}-\mathrm{R}_{\text {sample }}}{\mathrm{R}_{\text {control }}} \times 100
$$

Where:

AOA : Antioxidant activity

$\mathrm{R} \quad: \mathrm{R}_{\text {control }}$ and $\mathrm{R}_{\text {sample }}$ were the bleaching rates of $\beta$-carotene in reactant mix without antioxidant and with hull extracts or BHT, respectively.

\section{Preparation of cooked mackerel as a model system}

Ethanol extract of Vedoc sunflower hulls (EEV) was chosen and its antioxidant activity was examined on a fish (mackerel) model system according to Shahidi \& Pegg (1990). The hull extract was dissolved in $2 \mathrm{ml}$ of $99 \%$ ethanol (absolute) and added to the minced mackerel fish $(20 \%$ by weight of water) at the following concentrations (100, 500 and 1000 $\mathrm{ppm})$. These concentrations were used to test their antioxidant effectiveness (Onyeneho \& Hettiarachehy 1991). A sample with BHT (200 $\mathrm{ppm}$ ) and a control sample containing only $2 \mathrm{ml}$ of $99 \%$ ethanol without antioxidant were also prepared. Meat systems were thoroughly homogenized and cooked at $75 \pm 2^{\circ} \mathrm{C}$ (He \& Shahidi, 1997) in a thermostated water bath (Julabo Labortetechnik GMBH Sw 20 seelbach / Germany) for $30 \mathrm{~min}$., samples were cooled to room temperature, transferred into plastic bags and then stored for 7 days at $4 \pm 1^{\circ} \mathrm{C}$. Samples were analysed for lipid oxidation (TBA) and colour changes on days $0,1,3,5$ and 7 .

\section{Thiobarbituric acid (TBA)}

The TBA was determined spectrophotometrically according to the procedure described by Siu \& Draper (1978). Cooked fish samples $(10 \mathrm{~g})$ were homogenized in $25 \mathrm{ml}$ of $10 \%$ trichloroacetic acetic. The mixture was mixed and filtered. One milliliter of $0.06 \mathrm{M}$ thiobarbituric acid was added to $4 \mathrm{ml}$ aliquots of the filtrate and heated in a boiling water bath for $10 \mathrm{~min}$ for colour development. The absorbance was read at $532 \mathrm{~nm}$ using a spectrophotometer (Shimadzu UV-Visible Recording Spectrophotometer, Model UV 240 Graphtcord). The TBA values were expressed as milligrams of malonaldehyde / kilogram of dry sample. Triplicate analyses were performed on all mackerel samples.

\section{Measurement of colour}

Changes in the surface colour of the mackerel samples was measured in duplicate for each sample using a spectrophotometer with colour scale (Hunter, Lab. Scan XE, Reston, VA). This instrument was standardized against a white tile of Hunter Lab. Colour standard (LX No. 16379: $X=77.26, Y=81.94$ and $Z=88.14)$. Colour was expressed in terms of lightness $\left(\mathrm{L}^{*}-\mathrm{value}\right)$, redness $\left(\mathrm{a}^{*}-\mathrm{value}\right)$, and yellowness $\left(\mathrm{b}^{*}-\mathrm{value}\right)$.

\section{Proximate analysis}

Moisture, protein, lipid, ash and crude fiber contents of sunflower hulls and muscle of mackerel were determined according to AOCS (1998). All analysis was carried out in triplicate.

\section{RESULTS AND DISCUSSION}

Current usage of sunflower seed or its byproducts as human food is so low that it might be considered as underutilized. Its use, however as an animal feed is considerable and growing. For humans, sunflower seeds are used mainly as a snack, the seeds being roasted and eaten as peanuts and chestnuts. Decorticated sunflower seeds feature much more in vegetarian diets and are sold primarily in health food stores as an effective alternative protein source (Nwokolo, 1996). To prepare refined protein products from sunflower such as flour, concentrates, isolates, textured vegetable protein etc., thus sunflower seeds have to be decorticated. Hence, effective utilization of the hulls seems to be essential.

\section{Proximate composition of sunflower hulls}

Table (1) gives the proximate composition of the three sunflower hulls. Data revealed that Giza 1, Vedoc and White hulls contained 6.14, 5.69 and $4.33 \%$ protein; $1.65,2.20$ and $1.89 \%$ oil; $1.35,1.68$ and $1.89 \%$ ash; $20.05,18.28$ and $19.26 \%$ crude fiber, and $62.58,62.42$ and $64.22 \%$ nitrogen free extract (NFE), respectively. Earle et al. (1968) reported that sunflower hulls contained between $1.7-6.1 \%$ protein. Bau et al. (1983), reported $2.8 \%$ protein, $1.2 \%$ lipid, $2.5 \%$ ash and 0.2 ethanol soluble for sunflower seed hull.

\section{Extraction of phenolic compounds from sunflower seed hulls}

Table (2) shows the total extracted phenolic compounds from the three seed hulls using four extracting solvents namely, methanol (M), ethanol (E), acetone (A) and ethyl acetate (EA). Results generally, revealed that $\mathrm{M}$ and $\mathrm{E}$ extracted more phenolic 
Table 1: Proximate composition of different sunflower seed hulls

\begin{tabular}{lccc}
\hline & \multicolumn{3}{c}{ Sunflower hulls } \\
\cline { 2 - 4 } Analysis \% & Giza 1 & Vedock & White \\
\hline Moisture & $8.53 \pm 0.090$ & $9.80 \pm 0.05$ & $8.81 \pm 0.11$ \\
Protein & $6.14 \pm 0.025$ & $5.69 \pm 0.08$ & $4.33 \pm 0.06$ \\
Oil & $1.65 \pm 0.180$ & $2.20 \pm 0.15$ & $1.89 \pm 0.08$ \\
Ash & $1.35 \pm 0.140$ & $1.68 \pm 0.21$ & $1.49 \pm 0.02$ \\
Crude Fiber & $20.05 \pm 0.31$ & $18.28 \pm 0.27$ & $19.26 \pm 0.21$ \\
NFE $^{*}$ & $62.58 \pm 0.06$ & $62.42 \pm 0.11$ & $64.22 \pm 0.09$ \\
\hline
\end{tabular}

Data reported are the mean values with standard deviation (SD)

* NFE $=$ Nitrogen free extract

Table 2: Total phenolic compounds extracted from the three sunflower seed hulls using different solvents

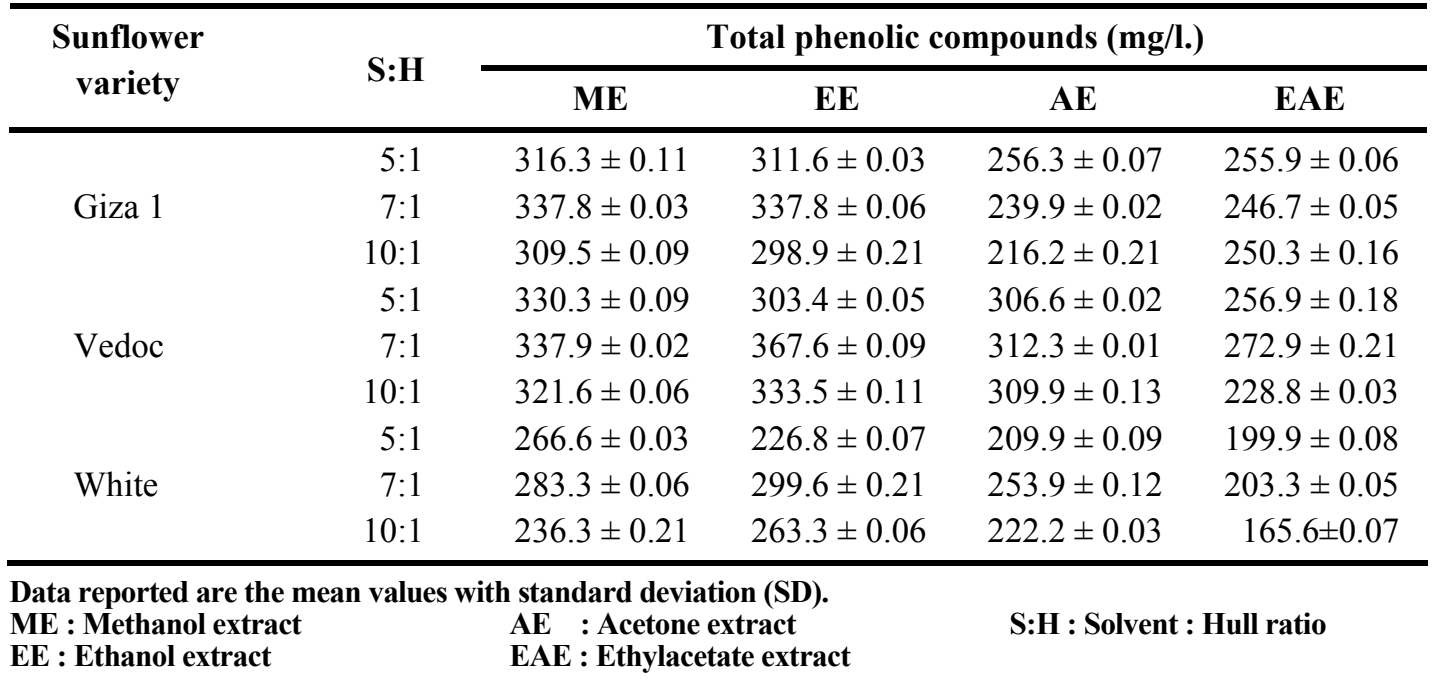

compounds than A and EA from the three types of hulls. The highest amount of total phenolic compounds was extracted from Giza 1 hulls using methanol (ME) and ethanol (EE) at a 7:1 solvent: hull ratio. The methanolic (ME) and ethanolic (EE) extracts from Vedoc and white hulls by using the previously mentioned ratio gave the following total phenolic compounds corresponding to $337.9,283.3,367.6$ and $299.6 \mathrm{mg} / \mathrm{l}$, respectively. On the other hand, A and EA extracted less phenolic compounds as compared to the other two solvents. In most cases 7:1 S:H ratio extracted more phenolic compounds except in the case of AE and EAE of Giza 1, where 5:1 was the optimum. Results obviously revealed that $\mathrm{E}$ was the most effective extracting solvent of phenolic compounds from sunflower seed hulls.

Bau et al. (1983) reported phenolic content of sunflower hulls to be $4.55 \%$ of sample of which $3.08 \%$ were in free state and $96.92 \%$ were bound. Velioglu et al. (1998), studied the antioxidant activity and total phenolics in selected fruits, vegetables and grain products. They found that sunflower hulls (purple) contained $9747 \mathrm{mg}$ total phenolics $/ 100 \mathrm{~g}$, while sunflower seed contained $1601 \mathrm{mg} / 100 \mathrm{~g}$. Pedrosa et al. (2000) used the HPLC for the determination of caffeic and chlorogenic acids and their derivatives in different sunflower seeds (kernels and hulls). They found that the total phenolic compounds $(\mathrm{g} / \mathrm{kg})$ of the hull in different genotypes of sunflower were 0.0780 for Tesoro, 0.376 for Marks, 0.2350 for Clip, 0.732 for Vyp and 0.1810 for Nanta. They added that the total phenolic compounds of kernels of different genotypes ranged between 1.6867 and $1.2867 \mathrm{~g} / \mathrm{kg}$ kernel.

Phenolic contents that were reported for other seed hulls included sesame coat which 
contained phenolic compounds and tetranortriterpenoids that contribute to its antioxidant activity (Chang et al. 2002). Hulls of ten legumes namely mung bean, field pea, lentil, fababean, pigeon pea, cowpea, navy bean, lima bean, chick pea and lupine were found to contain phenolic acids including p-hydroxybenzoic, protocatechuic, synergic, gallic, trans-pcoumaric and trans - ferulic acids that were present as both soluble esters and residues on alkaline hydrolysis of the hulls (Sosulski \& Dabrowski 1984). On the other hand, Yen \& Duh (1995), reported that the total phenolics of the hulls of four cultivars of peanut being in a range between $4.2-10.2 \mathrm{mg} / \mathrm{g}$ of hulls. The ethanolic extract of buckwheat hulls were reported to contain protocatechuic acid $4.3 \mathrm{mg} / 100 \mathrm{~g}$, rutin 4.3 $\mathrm{mg} / 100 \mathrm{~g}$, and quercitin $2.5 \mathrm{mg} / 100 \mathrm{~g}$ hulls (Watanabe et al. 1997). Phenolic compounds present in oat hulls as determined by GC-MS were ferulic acid, p-coumaric acid, vanillic acid, phydroxybenzoic acid, catechol, 4-hydroxyl phenyl acetate, o-coumaric, catechol, sinapic acid, and salycilic acid with a total of 3508 $\mathrm{mg} / \mathrm{kg}$ hull (Xing \& White 1997). Furthermore, Amarowicz et al. (2000), found that the total phenolic content of canola and rapeseed hulls ranged between 128 and $129 \mathrm{mg}$ of sinapic acid equivalents/ 1g of extract. Ramarathnam et al. (1988), reported on the presence of phenolic compounds in rice hull methanolic extract.

\section{Antioxidant activity of sunflower hull ex- tracts}

Table (3) gives the antioxidant activity (AOA\%) of different extracts of sunflower hull (Vedoc) along with different concentra- tions of BHT (50 and $200 \mathrm{ppm}$ ) as determined by the $\beta$-carotene/linoleate system at different time intervals. Figure (1) is a plot of the absorbance of different extracts of Vedoc hulls against time, the difference in absorbance between extracts and control is taken as an indicator for the AOA. It was clear from Table (3) and Fig. (1) that all Vedoc hull extracts exhibited AOA. Comparing the obtained results with synthetic antioxidants (BHT), the AOA of the examined extracts were in the following descending order: BHT-200 $>$ BHT-50 $>$ ME $>$ EE $>$ AE $>$ EAE. It is also worth to note that the extracts which showed relatively higher antioxidant activity (ME and EE) contained higher amount of total phenolic compounds (Table 2). The ME and EE possessed $92.88 \%$ and $90.47 \%$ of the antioxidant power of BHT-50, respectively, and $90.88 \%$ and $88.5 \%$ of the antioxidant power of BHT-200, respectively.

The obtained results also revealed the same pattern in antioxidative effects when the different extracts of sunflower variety (Giza 1) were investigated. The results of this variety are shown in Table (4) and Fig. (2).

From the aforementioned results, the antioxidants recovered from both ME and EE of sunflower hull (Giza 1 and Vedoc) proved their efficiency compared to BHT. So, this natural antioxidant can be applied successfully in food industries instead of using the synthetic one.

Velioglu et al. (1998) reported that the antioxidant activity (AOA\%) of methanolic extract of sunflower hull (purple) was $88.9 \%$, and

Table 3: Antioxidant activity of Vedoc sunflower hull extracted by different solvents at S:H $(7: 1)$

\begin{tabular}{lcccccc}
\hline \multirow{2}{*}{$\begin{array}{c}\text { Time } \\
\text { (min) }\end{array}$} & \multicolumn{7}{c}{ Antioxidant activity \% } \\
\cline { 2 - 7 } & ME & EE & AE & EAE & BHT-50 & BHT-200 \\
\hline 15 & $74.63 \pm 0.08$ & $66.79 \pm 0.34$ & $19.16 \pm 0.08$ & $86.60 \pm 0.16$ & $86.60 \pm 0.09$ & $94.75 \pm 0.35$ \\
30 & $86.51 \pm 0.13$ & $75.05 \pm 0.31$ & $69.12 \pm 0.36$ & $59.45 \pm 0.29$ & $96.64 \pm 0.04$ & $97.36 \pm 0.28$ \\
50 & $84.49 \pm 0.31$ & $84.06 \pm 0.19$ & $74.16 \pm 0.40$ & $54.56 \pm 0.15$ & $96.47 \pm 0.09$ & $97.58 \pm 0.06$ \\
70 & $91.60 \pm 0.26$ & $90.14 \pm 0.08$ & $80.64 \pm 0.09$ & $72.57 \pm 0.16$ & $97.30 \pm 0.16$ & $98.42 \pm 0.34$ \\
90 & $91.13 \pm 0.07$ & $90.71 \pm 0.23$ & $85.86 \pm 0.08$ & $83.85 \pm 0.22$ & $98.23 \pm 0.13$ & $98.38 \pm 0.18$ \\
110 & $91.08 \pm 0.17$ & $90.06 \pm 0.28$ & $85.35 \pm 0.34$ & $72.94 \pm 0.32$ & $96.63 \pm 0.28$ & $97.93 \pm 0.11$ \\
130 & $90.97 \pm 0.33$ & $86.40 \pm 0.31$ & $78.14 \pm 0.25$ & $70.64 \pm 0.28$ & $95.52 \pm 0.19$ & $97.41 \pm 0.09$ \\
150 & $88.50 \pm 0.09$ & $86.20 \pm 0.11$ & $72.67 \pm 0.22$ & $69.79 \pm 0.06$ & $95.28 \pm 0.17$ & $97.38 \pm 0.13$ \\
\hline
\end{tabular}

Data reported are the mean values with standard deviation (SD).

$M E$ : Methanol extract AE : Acetone extract

EE : Ethanol extract $\quad$ EAE : Ethylacetate extract

S:H : Solvent : Hull ratio 


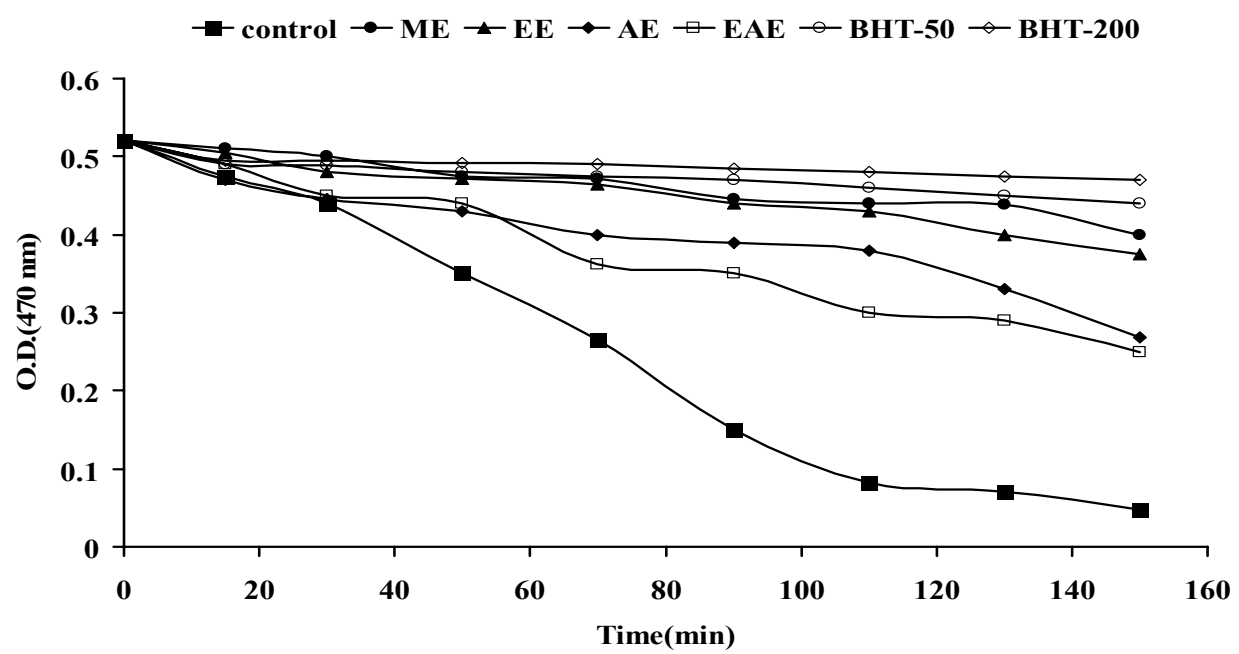

Fig. 1: Antioxidant activity of Vedoc sunflower hull extracted by different solvents at $\mathrm{S}: \mathrm{H}(7: 1)$ in a $\beta$-carotene / linoleate system as measured by changes in absorbance

Table 4: Antioxidant activity of sunflower hull (Giza 1) extracted by different solvents at S:H (7:1)

\begin{tabular}{ccccccc}
\hline \multirow{2}{*}{$\begin{array}{c}\text { Time } \\
(\text { min) }\end{array}$} & \multicolumn{7}{c}{ Antioxidant activity \% } \\
\cline { 2 - 7 } & ME & EE & AE & EAE & BHT-50 & BHT-200 \\
\hline 15 & $32.45 \pm 0.09$ & $29.16 \pm 0.23$ & $18.23 \pm 0.07$ & $7.18 \pm 0.01$ & $86.60 \pm 0.16$ & $94.75 \pm 0.31$ \\
30 & $79.84 \pm 0.09$ & $79.93 \pm 0.06$ & $68.07 \pm 0.16$ & $53.21 \pm 0.09$ & $96.64 \pm 0.13$ & $97.36 \pm 0.28$ \\
50 & $88.69 \pm 0.05$ & $88.77 \pm 0.13$ & $72.28 \pm 0.09$ & $54.63 \pm 0.23$ & $96.47 \pm 0.25$ & $97.58 \pm 0.08$ \\
70 & $90.80 \pm 0.12$ & $93.75 \pm 0.28$ & $74.81 \pm 0.22$ & $69.31 \pm 0.08$ & $97.30 \pm 0.06$ & $98.42 \pm 0.25$ \\
90 & $91.92 \pm 0.21$ & $94.29 \pm 0.08$ & $80.52 \pm 0.23$ & $79.85 \pm 0.09$ & $98.23 \pm 0.19$ & $98.38 \pm 0.22$ \\
110 & $89.79 \pm 0.06$ & $92.01 \pm 0.07$ & $83.84 \pm 0.05$ & $82.79 \pm 0.13$ & $96.63 \pm 0.05$ & $97.93 \pm 0.18$ \\
130 & $90.41 \pm 0.08$ & $90.12 \pm 0.31$ & $80.79 \pm 0.19$ & $77.18 \pm 0.32$ & $95.52 \pm 0.09$ & $97.41 \pm 0.07$ \\
150 & $88.62 \pm 0.16$ & $87.96 \pm 0.09$ & $71.73 \pm 0.30$ & $69.86 \pm 0.27$ & $95.28 \pm 0.08$ & $97.38 \pm 0.27$ \\
\hline
\end{tabular}

Data reported are the mean values with standard deviation (SD).
ME : Methanol extract
$\mathrm{AE}$ : Acetone extract
S:H : Solvent : Hull ratio

EE : Ethanol extract

EAE : Ethylacetate extract

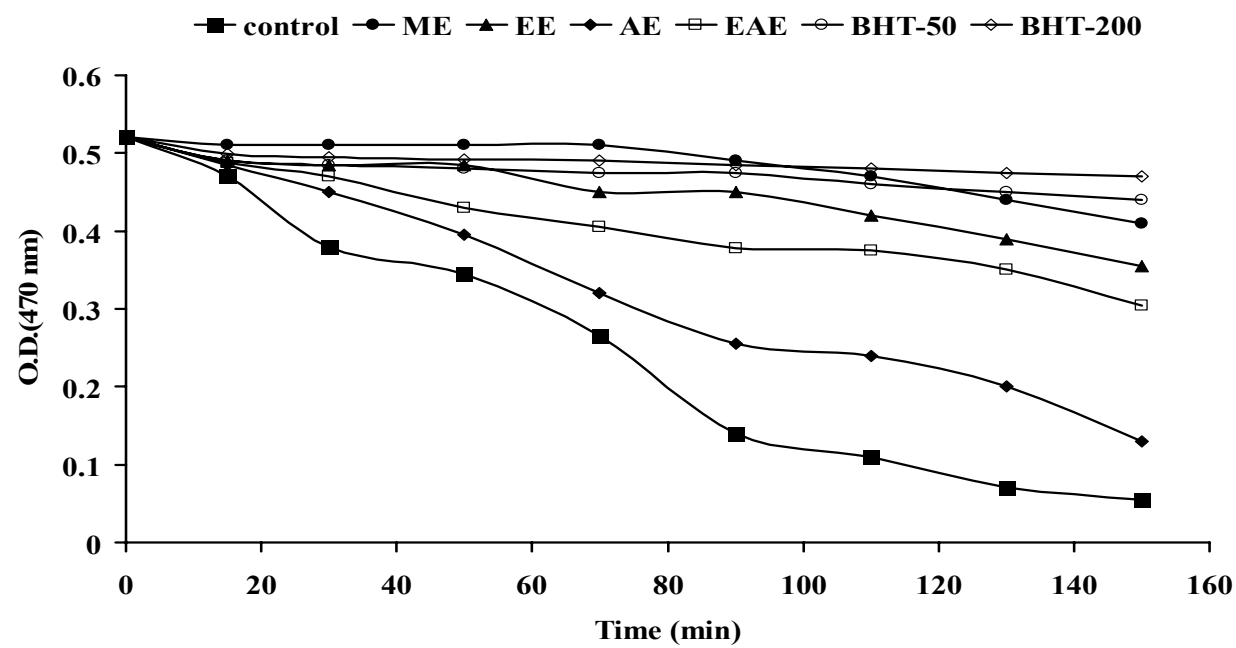

Fig. 2: Antioxidant activity of sunflower hull (Giza 1) extracted by different solvents at $\mathrm{S}: \mathrm{H}$ $(7: 1)$ in a $\beta$-carotene / linoleate system as measured by changes in absorbance 
its oxidation rate ratio (ORR) was 0.111 and its antioxidant activity coefficient (AAC) was 714.5. They reported BHT-200 and BHT-50 (mg/l) exhibited 97.2 and 84.3 AOA\%, respectively. Other investigators reported the AOA of other seed hulls. Ramarathnam et al. (1988), studied the hulls of two rice varieties namely Katakutara (Kat) and Kusabue (Kus). They found a strong antioxidant activity for crude methanolic extract of (Kat) rice hull, inhibited lipid peroxidation to the extent of $88 \%$ in comparison with rice hull (Kus) which inhibited lipid peroxidation to the extent of $81 \%$. However, both varieties showed AOA stronger than BHA and $\alpha$-tocopherol which showed inhibition of lipid peroxidation to the extent of $83 \%$ and $68 \%$, respectively. Chang et al. (2002), working on the seed coat of sesame proved that the AOA of $1.0 \mathrm{mg}$ ethanolic extract of sesame coat (EESC) was $91.4 \%$ and being rather equal to $1.0 \mathrm{mg}$ tocopherol $90.4 \%$ but was weaker than $1.0 \mathrm{mg}$ BHA $98.6 \%$. Amarowicz et al. (2000) found that crude tannin extract of canola hulls exhibited stronger AOA than rapeseed hulls. Duh et al. (1997) reported that the methanolic extract of mung bean hulls at a concentration of $100 \mathrm{ppm}$ exhibited stronger AOA than $100 \mathrm{ppm}$ BHA and $100 \mathrm{ppm}$ dl- $\alpha-$ tocopherol on the peroxidation of linoleic acid. The methanol hull extract also showed good inhibitory activity in soybean oil oxidation which was examined by peroxide value, thiobarbituric acid and gas chromatography of the fatty acid methyl esters. Xing \& White (1997), reported different concentrations of oat groats and hull extracts when added to soybean oil at $60^{\circ} \mathrm{C}$ and compared to TBHQ and a control (no additives) to act as an antioxidant as measured by peroxide value. The AOA of extracts of groat and hulls increased with concentration. Onyencho \& Hettiarachchy (1991), studied the effectiveness of freeze dried navy bean hull extract (NBHE) as an antioxidant, this was evaluated in storage studies with soy and sunflower oils. Monthly peroxide values determination indicated NBHE to be a stronger antioxidant than BHT-BHA mixture and rosemary (AR) but was less effective than TBHQ at all levels and storage conditions. Watanabe et al. (1997) separated ethanolic extract of buckwheat hulls by Sephadex LH-20 column chromatography into eight fractions. Five of the fractions exhibited peroxyl radical scavenging activity by inhibiting the oxidation of methyl linoleate in solution. Yen \& Duh $(1994,1995)$ reported that methanolic extract of peanut hulls (MEPH) showed marked activity as a radical scavenger in the experiments using $\mathrm{DPPH}^{*}$ radical. The MEPH also possessed AOA towards $\mathrm{H}_{2} \mathrm{O}_{2}$ and suuperoxide $\left(\mathrm{O}_{2}^{-}\right)$, it also exhibited a marked scavenging activity on hydroxyl radicals.

\section{Antioxidant activity of sunflower hull in fish meat as a model system}

Mackerel, a fatty fish, because of its high content of unsaturated fatty acids (He \& Shahidi, 1997) was chosen in the present study. The authors stated that the extension of shelf life of foods and especially fish may be achieved by addition of antioxidants. The antioxidant chosen in the present study to inhibit lipid oxidation was the ethanol extract of sunflower hull "Vedoc" (EEV). This choice was based on the fact that ethanol is more safer than methanol, acetone or ethyl acetate and therefore more suitable for the food industry. Vedoc is the sunflower hybrid used industrially for its high oil content, thus the availability of hulls is assured. The EEV was investigated in the fish model system at three levels $(100,500$ and $1000 \mathrm{ppm}$ ) along with BHT-200 ppm. and a control (minced mackerel meat with no addition), for comparison. Table (5) gives the proximate composition of the minced mackerel meat. Data revealed that mackerel meat contained moisture $(67.75 \%)$, protein $(18.63 \%)$, fat $(11.24 \%)$, and ash (1.34\%). These values are in agreement with those reported by $\mathrm{He} \&$ Shahidi (1997).

Table 5: Proximate composition of frozen mackerel

\begin{tabular}{lr}
\hline Components & Percentage \\
\hline Moisture & $67.75 \pm 0.30$ \\
Protein & $18.63 \pm 0.35$ \\
Fat & $11.24 \pm 0.04$ \\
Ash & $1.34 \pm 0.07$ \\
\hline
\end{tabular}

Data reported are mean values with standard deviation (SD)

Changes in TBA values of cooked mackerel fish: The TBA values of mackerel meat treated with different levels of EEV along with a sample treated with BHT and a control are presented in Table (6). It was clear that the addition of EEV at 100, 500 and $1000 \mathrm{ppm}$, delayed lipid oxidation for cooked mackerel compared to the control sample at all storage times. The EEV500 and EEV-1000 competed well with BHT- 
Table 6: Effect of ethanol extract of sunflower hulls (Vedoc) on the TBA values of cooked mackerel stored at $4^{\circ} \mathrm{C}$ (mg malonaldehyde / $\mathrm{kg}$ sample)

\begin{tabular}{ccccccc}
\hline \multirow{2}{*}{$\begin{array}{c}\text { Cooked } \\
\text { mackerel }\end{array}$} & ppm & \multicolumn{5}{c}{ Storage time (days) } \\
\cline { 3 - 7 } & & $\mathbf{0}$ & $\mathbf{1}$ & $\mathbf{3}$ & $\mathbf{5}$ & $\mathbf{7}$ \\
\hline \multirow{2}{*}{ Control } & & $9.00 \pm 0.10$ & $11.54 \pm 0.40$ & $14.54 \pm 0.03$ & $16.01 \pm 0.03$ & $17.38 \pm 0.20$ \\
& & & & & & \\
+ BHT & 200 & $5.20 \pm 0.31$ & $5.36 \pm 0.20$ & $6.31 \pm 0.10$ & $6.90 \pm 0.15$ & $7.42 \pm 0.40$ \\
& & & & & & \\
$+\mathrm{EEV}^{*}$ & 100 & $5.70 \pm 0.04$ & $6.40 \pm 0.01$ & $7.10 \pm 0.28$ & $8.06 \pm 0.09$ & $8.90 \pm 0.42$ \\
& 500 & $4.00 \pm 0.23$ & $4.40 \pm 0.03$ & $6.00 \pm 0.04$ & $6.31 \pm 0.03$ & $7.35 \pm 0.01$ \\
& 1000 & $3.40 \pm 0.02$ & $3.60 \pm 0.01$ & $4.50 \pm 0.03$ & $4.03 \pm 0.15$ & $5.72 \pm 0.05$ \\
\hline
\end{tabular}

Data reported are the mean values with standard deviation (SD).

* Ethanolic extract of Vedoc hulls.

200 in inhibiting the formation of thiobarbituric acid reactive substances (TBARS), but EEV100 was less effective than BHT-200 in the fish model system. It could be also noticed that TBARS formation either with the addition of EEV or BHT or without any addition was time dependent at $4^{\circ} \mathrm{C}$.

Figure (3) shows the \% inhibition of lipid oxidation as $\%$ of control. Results of Figure 3 confirmed results in Table (6). The highest \% inhibition of lipid oxidation was achieved with EEV-1000 followed by EEV-500. EEV at these two levels of addition surpassed BHT-200 in their power of inhibiting lipid oxidation in mackerel meat system. At day 7 , the $\%$ inhibi- tion of lipid oxidation (compared to control) reached $57.3 \%, 48.8 \%, 57.7 \%$ and $67.1 \%$ for BHT-200, EEV-100, EEV-500, and EEV-1000, respectively.

He \& Shahidi (1997) examined the AOA of green tea catechins in fish meat model system (mackerel). They monitored progression of oxidation by measuring changes in TBA and total volatiles of samples. They reported that samples treated with ground green tea leaves, tea extracts and pure catechins showed excellent oxidative stability as compared with samples that contained $\alpha$-tocopherol, BHT, BHA and TBHQ. Yu et al. (2002), reported that rosemary extracts (water-soluble) exhibited

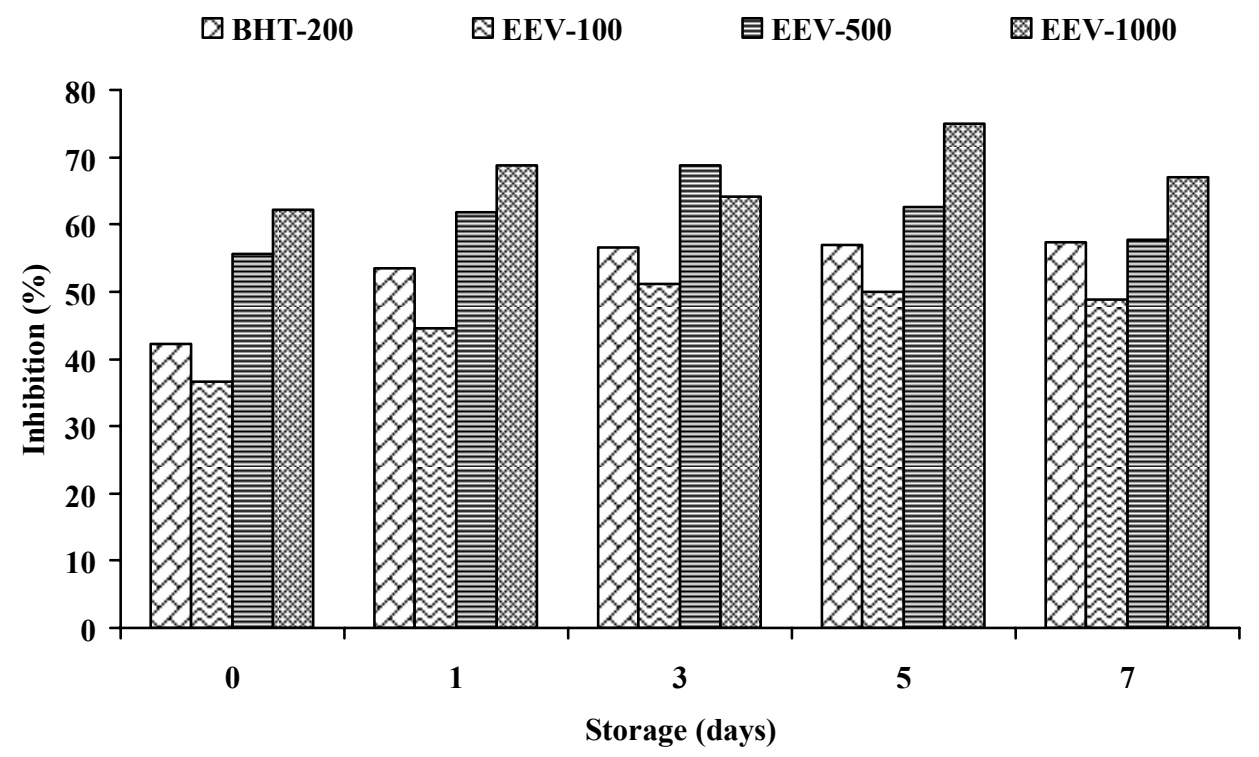

Fig. 3: Inhibition percentage of oxidation as measured by TBA in a mackerel meat model system 
significant protection of cooked turkey meat from lipid oxidation. Sanchez-Escalente et al. (2003a), prepared beef patties containing natural antioxidants- cayenne hot pepper, red sweet pepper, lycopene-rich tomato pulp, and extracts of tomato rich in lycopene, and packaged in modified atmosphere were evaluated for storage stability at $2 \pm 1^{\circ} \mathrm{C}$, by measuring colour surface metmyoglobin, TBA, psychrotropic bacteria counts and sensory off-odour and discolouration. Results revealed that lipid oxidation was found to be dramatically reduced $(\mathrm{P}<0.05)$ in beef patties containing the peppers, either hot or sweet. The TBA values were below 1 in both types of patties. Inhibition was even greater by the effect of cayenne hot peppers, which did not result in TBA elevation.

Sanchez-Escalaste et al. (2003b), also examined the antioxidant action of borage, rosemary, oregano and ascorbic acid in beef patties packaged in modified atmosphere. They reported that all the antioxidants except ascorbic acid reduced $(\mathrm{P}<0.01)$ TBA formation. Tang et al. (2001), studied the effect of tea catechins (TC) on improving oxidative stability of cooked chicken meat and beef compared with $\alpha$ tocopherol (VE). Oxidative stability (TBA) was measured on days 1, 3, 6 and 10. The susceptibility of cooked meat to lipid oxidation was species dependent. Chicken meat was more susceptible to oxidative deterioration than beef. There were no significant changes in TBA numbers during the course of the test for cooked beef containing either TC or VE at the levels of $300 \mathrm{mg} / \mathrm{kg}^{-1}$ meat.

Colour of cooked mackerel fish: The effect of addition EEV at different levels along with BHT on the surface colour characteristics of cooked mackerel meat is presented in Table (7) and Figs. (4 and 5). Results of $b^{*}$ values are not shown in figures because they follow the same trend as $\mathrm{L}^{*}$. The EEV clearly decreased the $\mathrm{L}^{*}$ (lightness) and $\mathrm{b}^{*}$ (yellowness) values of cooked mackerel meat when compared to the control. On the other hand, values of $\mathrm{L}^{*}$ and $\mathrm{b}^{*}$ for control and treated samples increased throughout the storage period. On day $0, \mathrm{~L}^{*}$ values for control, BHT-200, EEV-100, EEV 500 and EEV-1000 were 47.2, 46.24, 46.15, 45.54 and 45.2 , respectively, and $b^{*}$ values were 13.34 , $12.13,12.11,11.1$ and 10.15 , respectively.

At the end of the storage period, $\mathrm{L}^{*}$ values were 59.93, 48.91, 49.53, 47.31 and 46.15 for control, BHT-200, EEV-100, EEV-
500, EEV-1000, respectively, and $b^{*}$ values were 17.54, 14.95, 13.11, 12.92 and 11.6, respectively. The difference in colour between control and treated samples as demonstrated by $\mathrm{L}^{*}$ and $\mathrm{b}^{*}$ values increased with storage. On the other hand, values of $a^{*}$ decreased as storage time was elongated. On day $0, a^{*}$ value was 5.37 for control which decreased to 2.54 on day 7. The $a^{*}$ values for BHT-200 and EEV-100 were $6.76,4$ and 6.12 at the beginning of the experiment and decreased to 4.31 and 4.73 at the end of storage time. The addition of all antioxidants under study protected the mackerel meat from redness fading to varying degrees.

Sanchez- Esclante et al. (2003a) worked on the stabilization of colour and odour of beef patties by lycopene-rich tomato and peppers as a source of antioxidants. The antioxidant sources included cayenne hot pepper, red sweet pepper, lycopene rich tomato pulp (LRTP) and extract of tomato rich in lycopene (Lyc-o-Mato). Results demonstrated that the addition of ground peppers (both sweet and hot) to beef patties significantly inhibited $(\mathrm{P}<0.05)$ the oxidation of myoglobin and lipid. Regarding values of $\mathrm{L}^{*}$ and $b^{*}$ no trend or significant difference among treatments were traced while both peppers gave a dramatic $(\mathrm{P}<0.05)$ inhibition of metmyoglbin formation. Yet, both peppers gave the highest $\mathrm{a}^{*}$ values. All treatments resulted in decrease of ${ }^{*}$ colour of beef patties during the storage period. $\mathrm{Yu}$ et al. (2002) also worked on rosemary extract to inhibit oxidation of cooked turkey meat. They found that Hunter $\mathrm{L}^{*}$ values of cooked turkey meat at all tested storage periods significantly decreased when water-soluble rosemary extract (WSRE) was added. Turkey samples containing WSRE had higher a ${ }^{*}$ values than that of the control. Rosemary extracts delayed the decrease of the Hunter $\mathrm{a}^{*}$ values of cooked turkey significantly at all storage periods tested.

Sanchez- Esclante et al. (2003b) examined the antioxidant activity of oregano, borage rosemary and ascorbic acid in beef patties packaged in modified atmosphere. They found that $\mathrm{a}^{*}$ values decreased progressively during storage in all the beef patties (treated with antioxidants) and that values of $\mathrm{a}^{*}$ were significantly higher $(\mathrm{P}<0.01)$ than those of control between days 820 in patties treated with oregano. On day 4 of storage, the $\mathrm{a}^{*}$ values were similar for all samples $(\mathrm{P}<0.05)$ except those with rosemary (alone or with ascorbic acid), but after 8 days storage they varied significantly $(\mathrm{P}<0.01)$. 


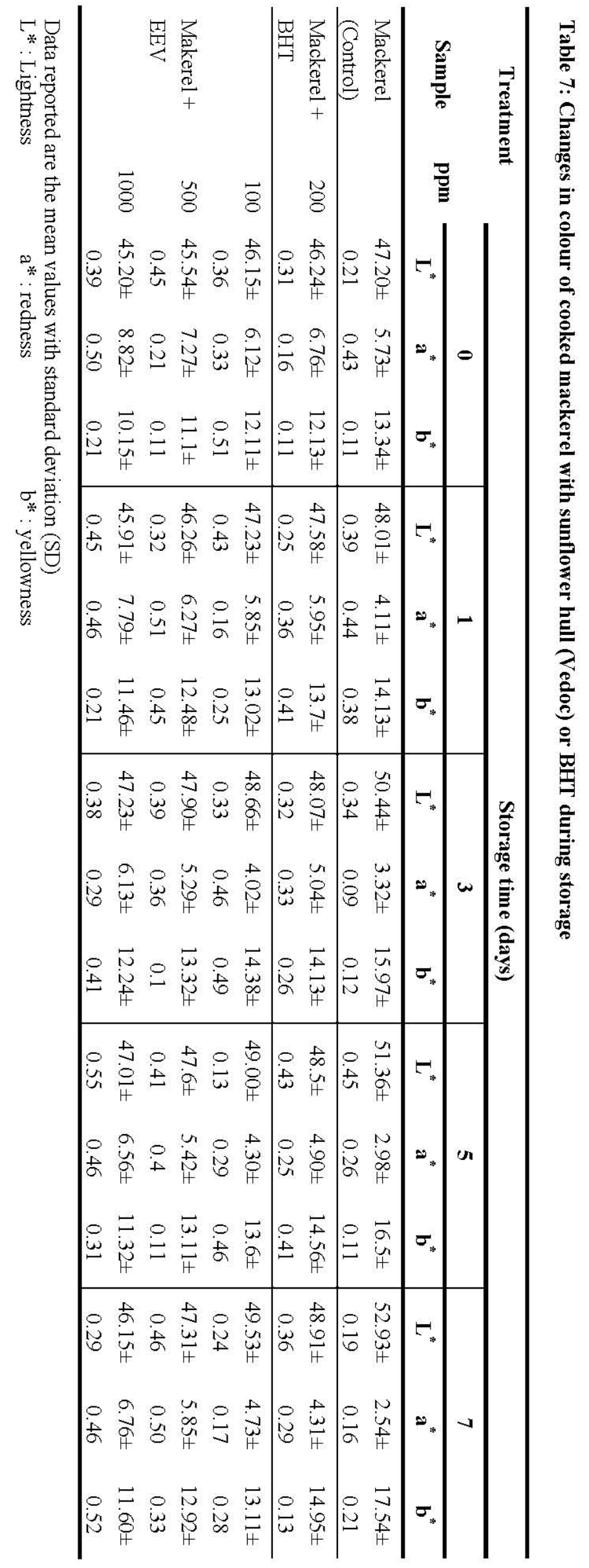




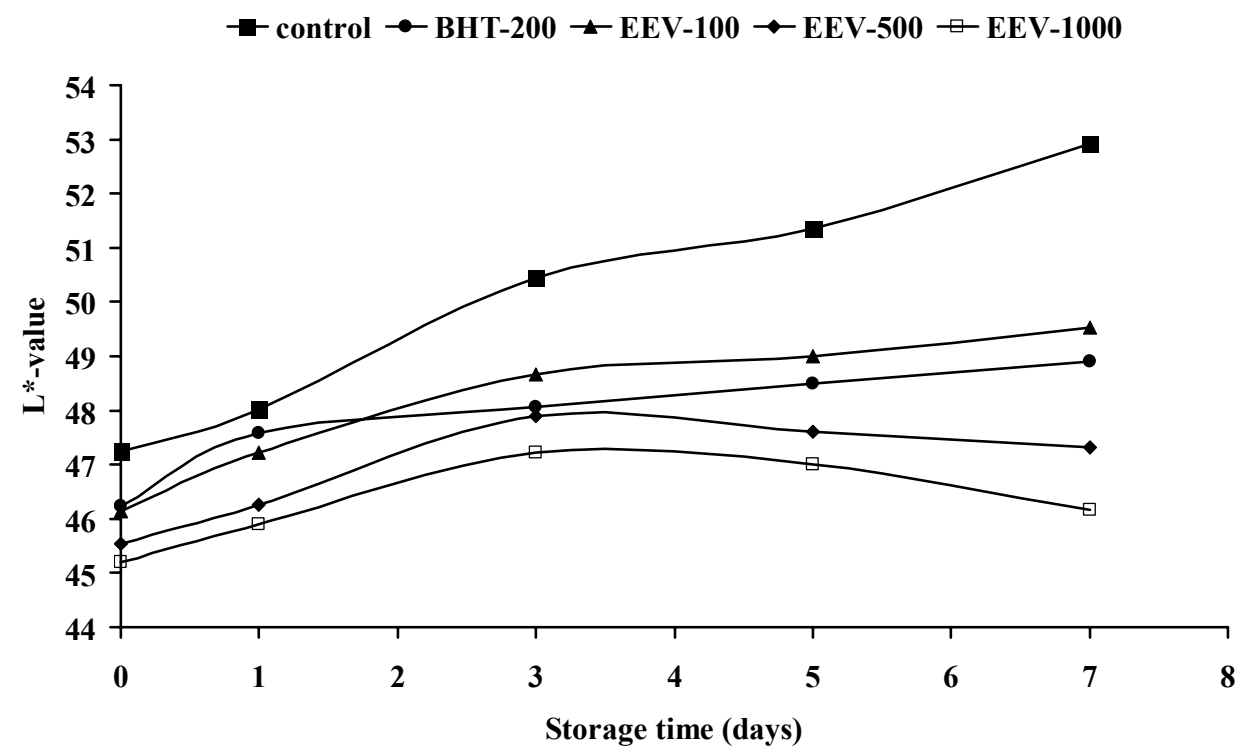

Fig. 4: Hunter $L^{*}$-value of cooked mackerel with sunflower hull (Vedoc) or BHT during storage EEV : Ethanolic extract of Vedoc hulls

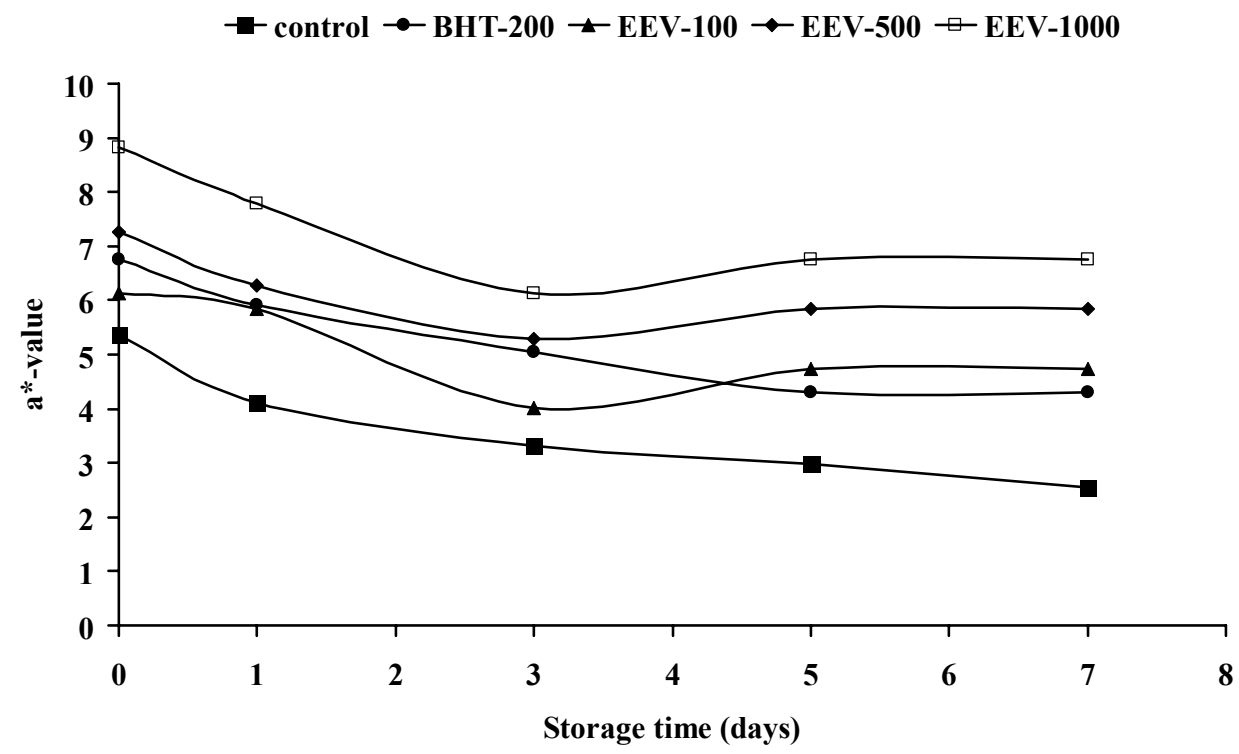

Fig. 5: Hunter a ${ }^{*}$-value of cooked mackerel with sunflower hull (Vedoc) or BHT during storage EEV : Ethanolic extract of Vedoc hulls

Previous results indicate that the potential use of the ethanolic extract of sunflower hulls (Vedoc) as an antioxidant has been confirmed by the $\beta$-carotene- linoleate method. The ethanolic hull extract has been also tested in a fish (Mackerel) meat model system and has been proved to delay oxidation of fish fat (TBA) as well as preserving the surface colour of fish meat as measured by Hunter Lab. In conclusion, ethanol extract of sunflower hull (Vedoc) presented a potential cheap natural source of antioxidant.

\section{REFERENCES}

Al-Shaikhan, M.S., Howard, L.R. \& Miller, J.C. JR. 1995. Antioxidant activity and total phenolics in different genotypes of potato. J. Food Sci. 60: 341-343.

Aly, S.M. \& Girgis, B. 2000. Bleaching of cotton seed oil using active carbon obtained from apricot stones. Modelling Measurement and control (AMSE) 61: 35-42.

Amarowicz, R., Naczk, M. \& Shahidi F. 2000. Antioxidant activity of crude tannis of canola and 
rapeseed hulls. J. Am. Oil chem. Soc. 77: 956-961.

AOCS, 1998. "Official Methods and Recommended Practices of the American Oil Chemist's Society" AOCS Press, Champaign, IL, $5^{\text {th }}$ edition.

Asamarai, A.M., Addis, P.B., Epley, R.J. \& Krick, T.P. 1996. Wild rice hull antioxidants. J. Agric. Food Chem. 44: 126-130.

Bau, H.M., Mohtadi-Nai, D.J., Mejean, L. \& Derby G. 1983. Preparation of colorless sunflower protein products: Effects of processing and physicological and nutritional properties. J. Am. Oil. Chem. Soc. 60: 1141-1148.

Chang, L.W., Yen, W. J., Huang, S.C. \& Duh, P.D. 2002. Antioxidant activity of sesame coat. Food Chem. 78: 347-354.

Crum, C.W., Prescott, J.M. \& Christensen, P.J. 1992. Genetic Approaches to Increased Nutritional Value in Oilseed Meal. Proceedings of the World Conference on Oil Seed Technology and Utilization. Ed. Apple White T.H. pp. 334-398, AOCS Press, Champaign, IL.

Duh, P.D. \& Yen, G.C. 1995. Changes in antioxidant activity and component of methanolic extracts of peanut hulls irradiated with ultraviolet light. Food Chem. 54: 127-131.

Duh, P.D., Yen, W.J., Du, P.C. \& Yen, G.C. 1997. Antioxidant activity of mung bean hulls. J. Am. Oil Chem. Soc. 74: 1059-1063.

Earle, F.R., Vanetten, C.H., Clark, T.F. \& Wolff, J.A. 1968. Composition data on sunflower seed. J. Am. Oil. Chem. Soc. 45: 876-879.

He, Y \& Shahidi, F. 1997. Antioxidant activity of green tea and its catechin in a fish meat model system. J. Agric. Food Chem. 45: 4262-4266.

Hung, Y.; Sava, V.M.; Makan, S.Y., Chen, T.H.J.; Hong, M.Y. \& Huang, G.S. 2002. Antioxidant activity of melanins derived from tea: Comparison between different oxidative states. Food Chem. 78: 233-240.

Ito, N., Hagiwara, A., Shibate, M., Ogiso, T. \& Fukushima, S. 1982. Induction of squampus cell carcinoma in the forestomach of F 344 rats treated with butylated hydroxy anisole.Gann Monographe on Cancer Research 73: 332334.

John, M.M. \& Marshall, W.E. 1994. Metal Absorption Using Granular Activated Carbons from Agricultural By-Products. I and EC Special Symposium of the American Chem. Soc. Atlanta.

Marco, G.J. 1968. A rapid method for evaluation of antioxidants. J. Amer. Oil Chem. Soc. 45: 594-598.

Nwokolo, E. 1996: Sunflower (Heliauthus annus, L.) In "Food and Feed from Legumes and Oil Seed" Editors, E. Nwokolo and Smartt, J., Chapter 28, Chapman \& Hall, NY.

Omar, S., Girgis, B \& Taha, F. 2003. Carbonaceous materials from seed hulls for bleaching of vegetable oils. Food Research International 36: 11-17.

Onyenecho, S.N. \& Hettiarachchy, N.S. 1991. Effect of navy bean hall extract on the oxidative stability of soy and sunflower oils. J. Agric. Food Chem. 39: 1701-1704.

Pedrosa, M.M., Muzquiz, M.G., Vallejo C., Burbano, C., Cuadrado, C., Ayet, G. \& Robredo, L.M. 2000. Determination of caffeic and chlorogenic acids and their derivations in different sun flower seeds. J. Sci. Food Agric. 80: $459-464$

Ramarathnam, N., Osawa, T., Namihi, M. \& Kawakishi, S. 1988. Chemical studies on novel rice hull antioxidants I. Isolation, fractrionation, and partial characterization. J. Agric. Food Chem. 36: 732-737.

Sanchez-Escalante, A., Torrescano, G., Djenane, D., Beltran, J.A. \& Roncales, P. 2003a. Stabilisation of colour and odour of beef patties by using lycopene-rich tomato and peppers as a source of antioxidants. J. Sci. Food Agric. 83: 187-194.

Sanchez-Escalante, A., Djenane, D., Torrescano, G., Beltran, J.A. \& roncales, P. 2003b. Antioxidant action of borage, rosemary, oregano and ascorbic acid in beef patties packaged in modified atmosphere. J. Food Sci. 68: 339349.

Shahidi, F. \& Pegg, R.B. 1990. Colour characteristics of cooked cured meat pigments and its application in meat. Food Chem. 38: 61-68.

Siu, G.M. \& Draper, H.H. 1978. A survey of the malonaldehyde content of retail meats and fish. J. Food. Sci. 43, 1147-1149.

Sosulski, F.W. \& Dabrowski, K.J. 1984. Composition of free and hydrolyzable phenolic acids in the flours and hulls of ten legume species. J. Agric Food Chem. 32: 131-133.

Tang, S., Kerry, J.P., Sheehan, D. \& Buckley, D.J. 2001. A comparative study of tea catechins and $\alpha$-tocopherol as antioxidants in cooked beef $\&$ chicken meat. Eur Food Res. Technol. 213: 286-289.

Velioglu, Y.S., Mazza, G., Goa, L. \& Oomah, B.D. 1998. Antioxidant activity and tobal phenolics in selected fruits, vegetables and grain products. J. Agric. Food Chem. 46: 41134117.

Watanabe, M., Ohshita, Y. \& Tsushida, T. 1997. Antioxidant Compounds from Buckwheat hulls, J. Agric Food Chem. 45: 1039-1044.

Wu, Kejian, Zhang, W., Addis, P.B., Epley, R.J., Salih, A.M. \& Lehrfeld, J. 1994. Antioxidant property of wild rice. J. Agric. Food Chem. 42: 43-37.

Xing, Y. \& White, J.P. 1997. Identification and function of antioxidants from oat groats and hulls. J. Am. Oil Chem. Soc. 74: 303-307.

Yagi, K. 1990. Lipid peroxides and human disease. Chemistry and physics of lipids 45: 337-341. 
Yen, G.C. \& Duh, P.D. 1994. Scavenging effect of methanolic extract of peanut hulls on free radical and active oxygen species. J. Agric Food Chem. 42: 629-632.

Yen, G.C. \& Duh, P.D. 1995. Antioxidant activity of methanolic extracts of peanut hulls from various cultivars. J. Am. Oil. Chem. Soc. 72: 1065-1067.
Yu, L., Scanlim, L., Wilson, J. \& Scllmid, T.G. 2002. Rosemary extract as inhibitors of lipids oxidation and color change in cooked Turkey products during refrigerated storage. J. Food. Sci. 67 (2) 582-585.

\section{مستخلصات قصرة بذور دوار الشمس: \\ نشاطها المضاد للأكسلدة على ليبيلات سمك الماكريل المطهي

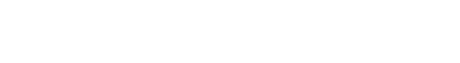 \\ 'قشم الصناعلت الغذائية، المركز القومع للبحوث، القاهرة، مصرر. \\ "ُقمم الزيوت والدهون ، المركز القومع للبحوث، القاهرة، مصر.}

لستخلصت المركبت الفينولية الموجوة فى قصرة ثلاثة أصنف من بذور دوار الثنهس annus L) الأسيتون، خلات الإيثيل) بنسب لستخلاص مختلفة [قصرة (وزن) : مذيب (حبم)]. أوضحت النتائج أن لستخدلم

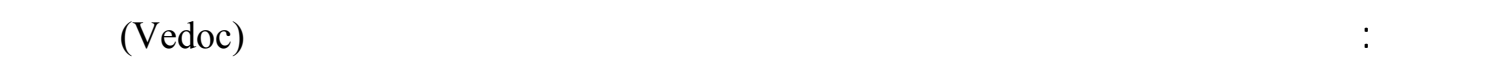

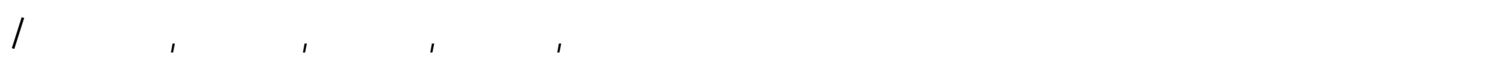

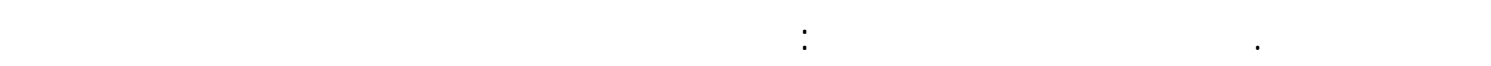

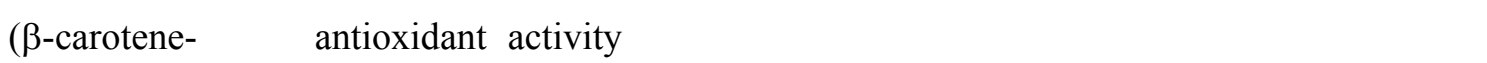
(Vedoc linoleate) لها ششلط مضاد للأكسة والق تدرجت فى فعاليتها كالآتى (الميثانول>، الايثانول> الاسيتون> خلات الإيثيل).

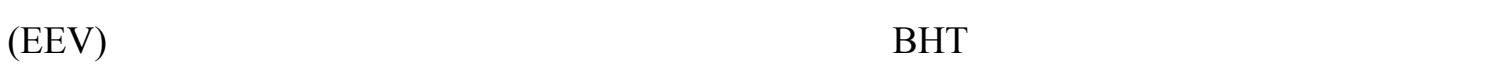

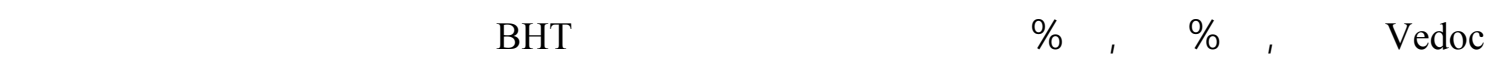

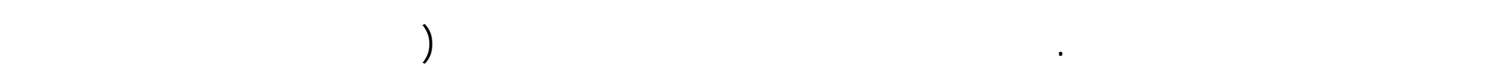

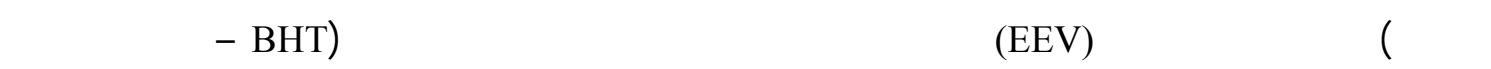
المليون) وذلك للمقارنة إلى مفرومسمك الملكربل ثم طهيه على درجة حرارة

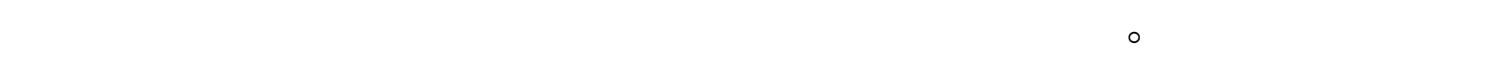
(TBA)

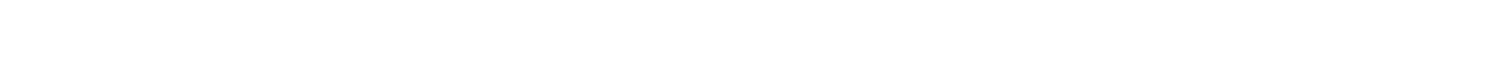

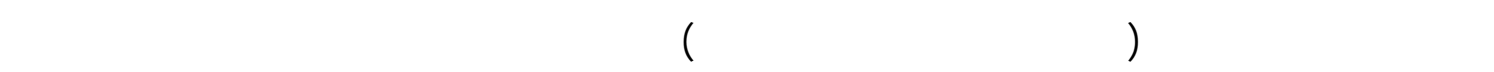

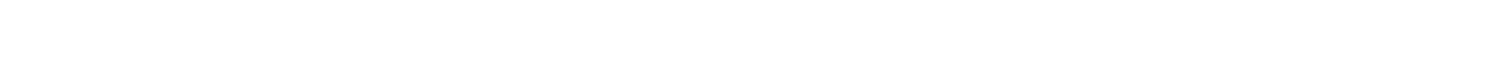

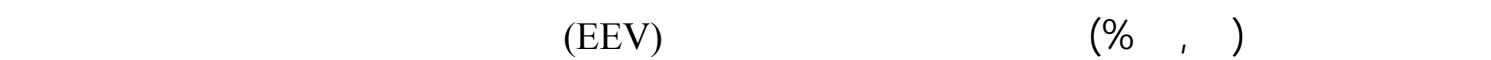
الخلهس عند عْم. 
